\title{
Somatosensory evoked potentials and outcome in perinatal asphyxia
}

\author{
N A Gibson, M Graham, M I Levene
}

\begin{abstract}
Somatosensory evoked potentials (SEP) can be measured in the term newborn infant and given an index of function in the areas of the brain most likely to be damaged in perinatal asphyxia. We studied the median nerve SEP in $\mathbf{3 0}$ asphyxiated term infants over the course of their encephalopathy and until discharge from the neonatal unit. Three types of response were noted: normal waveform, abnormal waveform, or absence of cortical response.

Follow up of the survivors was undertaken at a mean age of 12 months by means of a Griffiths' assessment and neurological examination. Nine infants died of their asphyxial illness and one of spinal muscular atrophy. Of the 20 survivors, three have cerebral palsy, four have minor abnormalities, and 13 are neurodevelopmentally normal.

There was a close correlation between outcome and SEP. All 13 infants with normal outcome had normal SEP by 4 days of age, whereas those with abnormal or absent responses beyond 4 days had abnormalities at follow up.
\end{abstract}

Perinatal asphyxia remains the single most important cause of neurodevelopmental handicap in the term newborn infant. The prognosis of the surviving infant is of importance both to the paediatrician deciding on follow up and physiotherapy and to the parents. The literature contains many reports of attempts to assess the prognosis using clinical examination, biochemical measurements, Doppler ultrasound assessment of cerebral blood flow velocity, electroencephalography (EEG), and computed tomography. ${ }^{1-7}$ Each of these techniques is subject to inaccuracy. Two previous papers have discussed the use of somatosensory evoked potentials (SEP) in perinatal asphyxia on small numbers of infants. ${ }^{89}$

We undertook to investigate the use of SEP in the prognostic assessment of a group of asphyxiated term infants. The parts of the brain most vulnerable to damage in this condition are the cortex, the immediate subcortical white matter, and the periventicular white matter. ${ }^{10}$ The somatosensory pathway traverses these areas and it seems reasonable to suppose that damage to these areas may be reflected in abnormalities of SEP.

Patients and methods

Between May 1987 and December 1988 term infants were recruited from the neonatal unit of Leicester Royal Infirmary after a full explanation to the parents. Ethical approval had been obtained from the local ethical committee. The infants were selected on the basis of term delivery; the presence of adverse perinatal factors consistent with an asphyxial insult, such as an abnormal cardiotocograph, low scalp $\mathrm{pH}$, cord prolapse or uterine rupture; and the presence of abnormal neurological findings in the neonatal period consistent with an asphyxial insult. The hypoxic-ischaemic encephalopathy was graded according to the description by Levene $e t a l^{11}$ modified from the Sarnat scheme. ${ }^{2}$

Thirty term infants with a mean gestational age of 39.5 weeks were recruited. Five were very small for dates ( $<3$ rd centile). All had clinical evidence of perinatal asphyxia and, in addition, one was subsequently shown to have spinal muscular atrophy and two had group $B \beta$ haemolytic streptococcal septicaemia, one of whom also had meningitis. Eight of the infants had mild encephalopathy and were neurologically normal by 3 days of age; six of the infants were moderately encephalopathic with more noticeable abnormalities of tone and seizures; the remaining 16 infants were severely asphyxiated. In addition, during the time of the study, there were two other infants fulfilling the enrolment criteria who did not take part. One infant died at 3 hours of age before he could be studied and the parents of one infant did not give consent for the study.

Median nerve SEP were recorded as soon as possible after admission to the neonatal unit and until resolution of the encephalopathy or death. Planned intervals between studies were every two days in the first week and twice a week thereafter. A hand held stimulator device delivering 1024 electrical impulses of $0.1 \mathrm{~ms}$ duration over the median nerve at a frequency of $5 \mathrm{~Hz}$ was employed. Normally three runs on each median nerve would be recorded. The response in the first $100 \mathrm{~ms}$ (sweep time) after each stimulus was recorded from silver/silver chloride skin surface electrodes over the cervical cord $(\mathrm{Cv} 2)$ and the contralateral cortex $\left(\mathrm{C}^{\prime \prime} 3\right.$ and $\left.\mathrm{C}^{\prime 4} 4\right)$ with a reference electrode in a midline frontal position (Fpz). An earth electrode was placed on the forearm. When this arrangement failed to evoke measurable potentials, the stimulus was delivered at $1 \mathrm{~Hz}$ for 256 or 512 stimuli and the sweep time increased to $200 \mathrm{~ms}$. The signals were fed to a Medelec Sensor evoked potential system for amplification, filtering using a $10-3000 \mathrm{~Hz}$ bandpass, averaging, and display. Sleep state could not be accurately assessed and would have been
Yorkhill, G3 8SJ.

Accepted 14 October 1991 
distorted in many of the infants by the use of anticonvulsants, but a visual inspection of behaviour was made. The acutely ill infants had regular estimations of blood glucose performed by reagent strips (BM-Test $1-44$, BM Diagnostics) to exclude hypoglycaemia which may effect evoked potentials. ${ }^{12}$ Oxygen monitoring by transcutaneous electrodes ensured that recordings were not done in the presence of hypoxia.

The SEP traces obtained were stored on an Apple IIe microcomputer for later analysis. The features assessed in the SEP were the shape of the cervical and cortical waveforms, and the latency of the cervical $\mathrm{C} 2$ potential (the major cervical potential) and cortical $\mathrm{Nl}$ (thought to be the first response of the primary somatosensory cortex). The comparative normal values were taken from our own study of $\mathbf{4 0}$ normal term infants. ${ }^{13}$

All the surviving infants were followed up and assessed at one year of age. This assessment was done by an investigator (MG) unaware of the SEP results or the extent of the encephalopathy. One infant was assessed by his local paediatrician. The other 19 infants were seen in their own homes and had a Griffiths' assessment ${ }^{14}$ and a neurological examination performed. The data available, therefore, were the Griffiths' subscale scores the Griffiths' quotient (GQ) and the neurological findings.

\section{DEFINITIONS}

In our study of normal term infants ${ }^{13}$ we showed that there was marked variation in both waveform and latency within the range of postmenstrual age 37 to 43 weeks. A strong positive correlation was found between increasing complexity of waveform with shortening of latencies and increasing postmenstrual age. The mean (SD) cervical potentials showed little variability with $\mathrm{C} 2$ latency $10 \cdot 1(0 \cdot 7) \mathrm{ms}$. The $\mathrm{N} 1$ for the whole group was $30 \cdot 1(6 \cdot 8)$ but much less widely scattered data were obtained within each of the four waveforms encountered. It was decided to base a decision of abnormality on the appropriateness for the infant's postmenstrual age of the measured waveform and the latency of the measured $\mathrm{Nl}$ for that waveform. The upper limit of normal latency was taken as the mean plus 3 SD because the control data on normal infants were slightly skewed to the left. We found on repeated runs that normal immature infants may initially have absent cortical potentials that are uncovered by an increase in stimulus intensity or decrease in stimulus frequency and hence the manoeuvres described above were employed to attempt to uncover a waveform when the initial runs showed no potentials.

In the present study of asphyxiated infants the results obtained from cortical electrodes in each individual recording session could then be split into three main groups. (1) Normal: responses appropriate in both latency and waveform for the infant's postmenstrual age. (2) Abnormal: measurable response with either delayed N1 ( $>+3 \mathrm{SD}$ from mean) for the encountered (appropriate) waveform or inappropriately immature waveform with normal N1 latency for that form. (3) Flat: complete absence of identifiable response-that is, flat traces on repeated runs.

\section{Results}

SEP

A total of 111 studies were performed on the 30 infants giving a mean of 3.7 and a mode of three studies. Three infants had only one study before death and the largest number in any one infant was 10 studies. Eighteen infants were studied on day 1 , seven were first studied on day 2 , four first studied on day 3, and one on day 7 . Cervical SEP were easily measured in all but one infant who was studied only a few hours before death, revealing no measurable potentials. In the other 29 infants cervical potentials were always normal even in those infants who had suffered shoulder dystocia during delivery (two infants).

The usual pattern over the course of the encephalopathy was for a progression of results from abnormality to normality. Asymmetry of response did occur but was seldom marked except in infant 20 (see below). Eleven infants had persistently normal SEP throughout their encephalopathy (pattern A). In addition, a further two infants had abnormal SEP with delayed latency of $\mathrm{N} 1$ in the first two days but normal SEP results thereafter (pattern B). Nine infants had initial potentials which were absent or severely abnormal and then the potentials were abnormal or absent for a variable length of
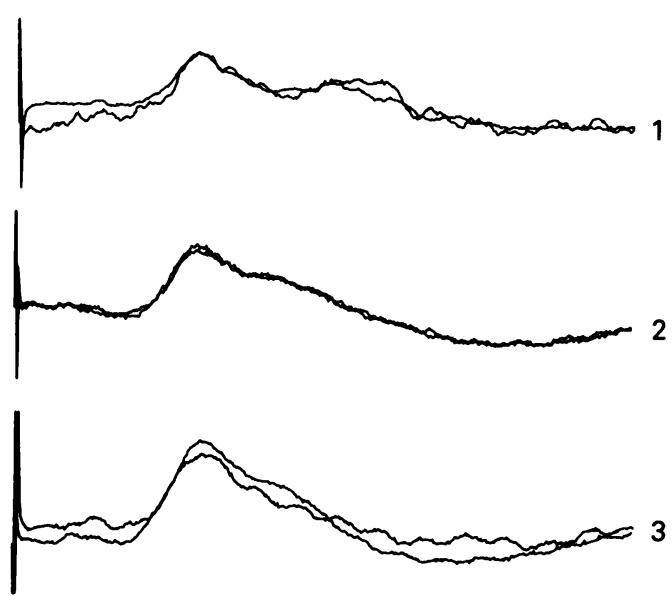

Figure 1 Infant 4(41 weeks' gestation). Superimposed traces of response to left median nerve stimulation measured at $C^{\prime \prime} 4-F$ p $z$ on days 1, 2, and 3: pattern $A$.

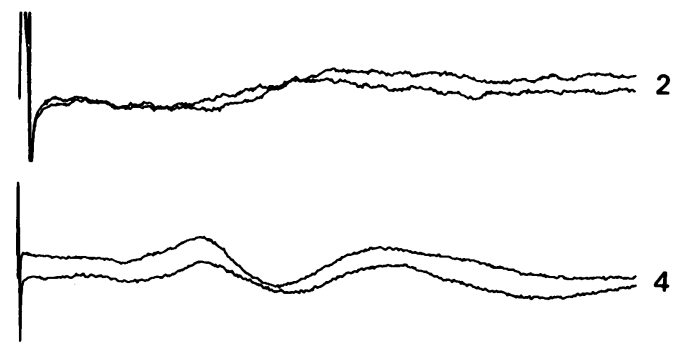

Figure 2 Infant 29 (42 weeks' gestation). Superimposed traces of response to left median nerve stimulation measured at $C^{\prime \prime} 4-F p z$ on days 2 and 4 : pattern $B$. 
time before returning in an immature fashion in which they persisted or normalised (pattern $\mathrm{C}$ ). In the other eight infants, all of whom had severe encephalopathy, the findings were of persistently flat traces with no cortical response measured at any time (pattern D). Examples of patterns A, $B, C$, and $D$ are shown in figs $1-4$.

\section{OUTCOME}

Ten of the infants in the study died. All of these infants had a pattern of neurological abnormality consistent with severe hypoxic-ischaemic encephalopathy. They died between 2 and 70 days but mostly in the first week of life.

The surviving infants were followed up to assess their outcome. One infant was seen by his local paediatrician and thought to be neurodevelopmentally normal. The results of the Griffiths' assessment subscales and GQ scores are available for 19 infants who were seen at a mean age of 12 months (range 9.5 to 14.5 months). They showed a wide range of results from 64 to 123. On neurological examination there were three infants with cerebral palsy, two of whom had spastic quadiplegia and were developmentally delayed (GQ 64 and 72) and one with a left hemiplegia (GQ 110). There were four other infants with low GQ scores $(72,85$, 87 , and 90 ) and questionable neurological find-
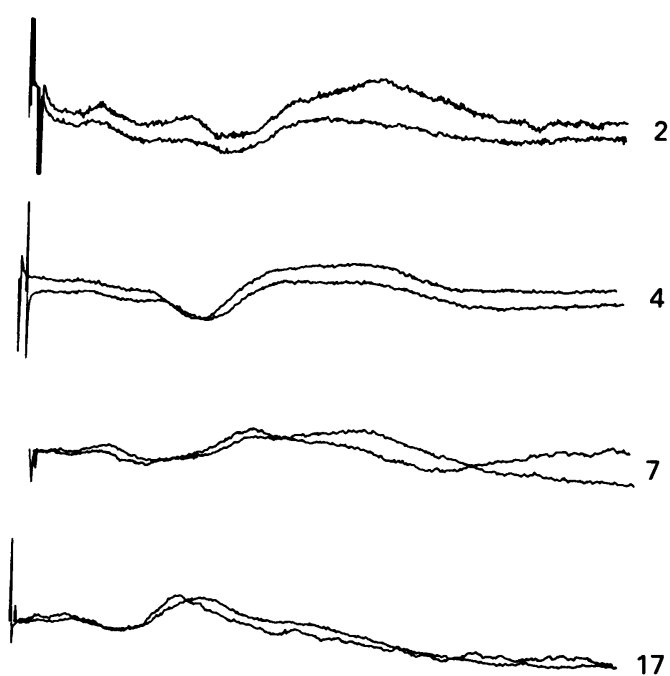

Figure 3 Infant 20 (39 weeks' gestation). Superimposed traces of response to right median nerve stimulation measured at $C^{\prime \prime} 3-F$ pz on days $2,4,7$, and 17: pattern $C$.
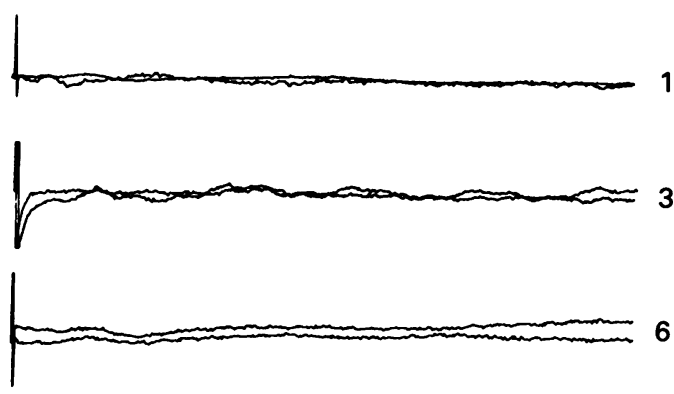

Figure 4 Infant 14 (40.5 weeks' gestation). Superimposed traces of response to right median nerve stimulation measured at $C^{\prime \prime} 3-F p z$ on days 1,3 , and 6: pattern $D$. ings who are best described as 'dystonic.' There are therefore three outcome groups among the survivors: unequivocal normality with normal neurology and high Griffiths' score, dystonic infants with questionable neurological findings and GQ scores in the lower part of the normal range, and those with clear abnormality manifest as cerebral palsy.

\section{CORRELATION OF SEP WITH OUTCOME}

The relationship of outcome to encephalopathy grade is shown in table 1 and is comparable with other studies reported in the literature. Table 2 shows the relationship of outcome to SEP pattern. The infants' outcome results were divided into normal outcome (13 infants), which was unequivocal neurological normality with normal GQ score, and abnormal outcome (seven infants) which includes the three infants with cerebral palsy and four in the dystonic group. The serial SEP results of those whose SEP changed over the course of their encephalopathy are shown in table 3. Those that had a normal outcome had reached normal SEP results by 4 days of age. All seven of the infants in the abnormal outcome group had abnormal SEP studies persisting beyond 4 days. There was no clear difference between those with cerebral palsy and the dystonic infants in terms of length of persistence of SEP abnormality nor of its pattern.

Of the 10 infants who died, eight had absent cortical SEP on all occasions. The infant who died of spinal muscular atrophy had normal cortical potentials. The other infant who died of cardiovascular complications of his asphyxia infant 15) had bilaterally abnormal potentials at day 5 and then persisting asymmetry thereafter. Therefore no infant dying of asphyxia had normal potentials by 4 days.

\section{Discussion}

From the literature there are a number of investigations which can assign a good prognosis to an asphyxiated infant. These are the presence of only grade one hypoxic-ischaemic encephalopathy, ${ }^{215}$ a normal $\mathrm{EEG}^{2}$ or a normal computed tomogram in the second week of life. ${ }^{7}$ It is

Table 1 Relationship of encephalopathy grade to outcome

\begin{tabular}{|c|c|c|c|c|c|}
\hline \multirow[t]{2}{*}{ Encephalopathy } & \multicolumn{4}{|l|}{ Outcome } & \multirow[t]{2}{*}{ Total } \\
\hline & Normal & Dystomic & $\begin{array}{l}\text { Cerebral } \\
\text { palsy }\end{array}$ & Died & \\
\hline $\begin{array}{l}\text { Mild } \\
\text { Moderate } \\
\text { Severe }\end{array}$ & $\begin{array}{l}8 \\
4 \\
1\end{array}$ & $\begin{array}{l}0 \\
1 \\
3\end{array}$ & $\begin{array}{l}0 \\
1 \\
2\end{array}$ & $\begin{array}{r}0 \\
0 \\
10\end{array}$ & $\begin{array}{r}8 \\
6 \\
16\end{array}$ \\
\hline
\end{tabular}

Table 2 Relationship of SEP pattern to outcome

\begin{tabular}{llllll}
\hline SEP & Outcome & & \multicolumn{3}{c}{ Total } \\
\cline { 2 - 5 } & Normal & Dystonic & $\begin{array}{l}\text { Cerebral } \\
\text { palsy }\end{array}$ & Died & \\
\hline A & 10 & 0 & 0 & $1^{*}$ & 11 \\
B & 2 & 0 & 0 & 0 & 2 \\
D & 1 & 4 & 3 & 1 & 9 \\
D & 0 & 0 & 0 & 8 & 8
\end{tabular}

See text for definition of patterns

${ }^{*}$ Child with spinal muscular atrophy. 


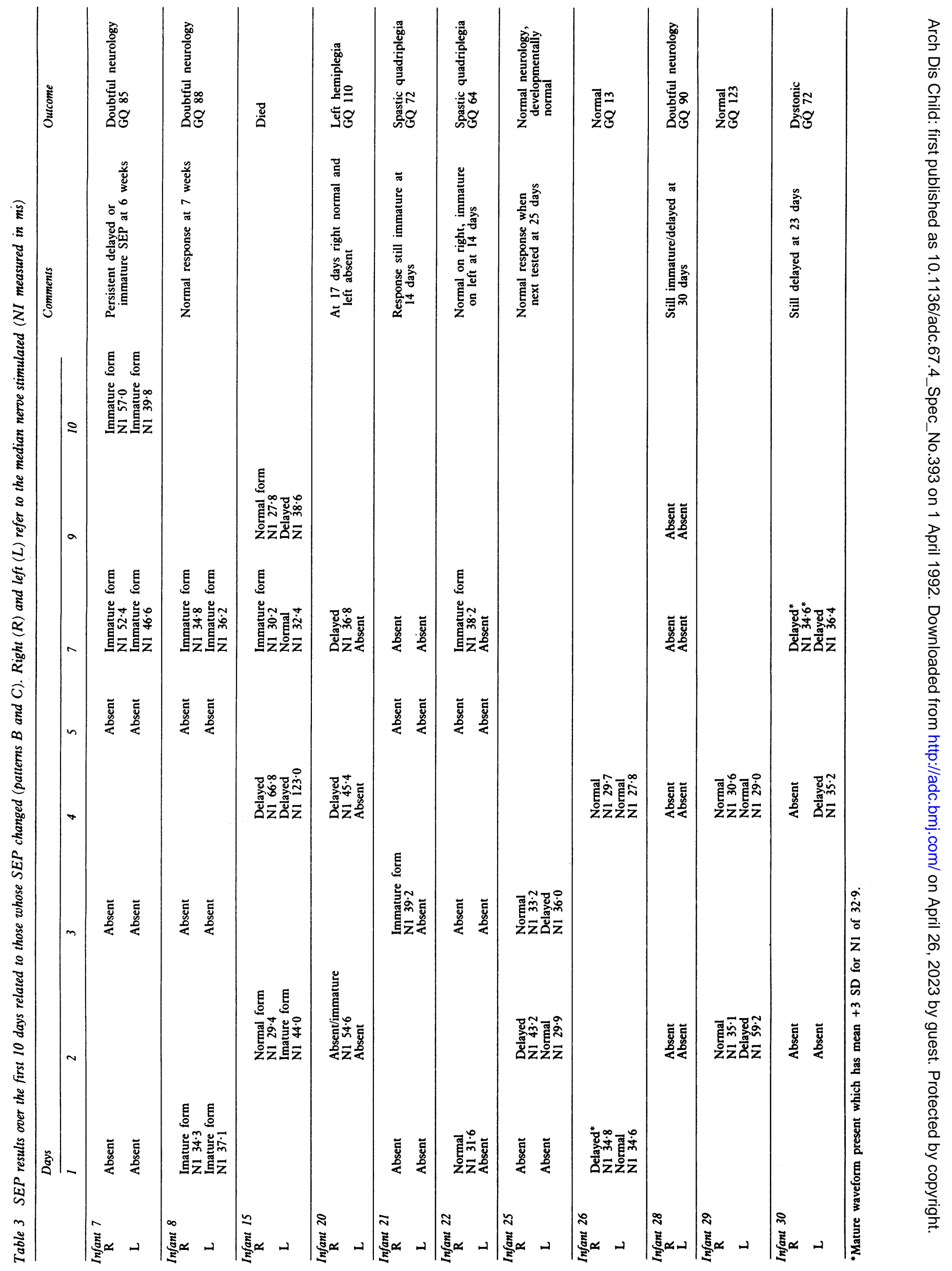


almost as clearcut to pick out those infants at extremely high risk of abnormal neurodevelopmental outcome on the basis of an isoelectric EEG ${ }^{5}$ extensive hypodensity on computed tomography, ${ }^{6}$ severe brain energy depletion shown by ${ }^{31} \mathrm{P}$ nuclear magnetic resonance spectroscopy, ${ }^{16}$ marked abnormality of Doppler signals from assessment of cerebral blood flow velocity, ${ }^{4}$ or profound and persisting neurological abnormality. ${ }^{1}$ However, these investigations all leave a grey area of infants with the same test result and differing outcome. The attraction of SEP is the ability to measure an index of function in the areas of the brain most severely affected in perinatal asphyxia.

There have been two previous studies of SEP in perinatal asphyxia. Hrbek et al described the use of SEP and visual evoked potentials in 57 infants. ${ }^{8}$ Their study is very difficult to assess as they do not state the gestational age of their patients, the method is not described, and there is no data on follow up. However, they developed a scoring system of SEP abnormality and reported those with the highest score (most abnormal SEP) to have the worst asphyxia. A more complete study by Willis and colleagues looked at 10 term asphyxiated infants followed up to a mean of 20 months. ${ }^{9}$ These authors aimed to perform SEP at 2, 4, and 6 months and defined abnormality as $\mathrm{Nl}$ absent or more than 3 SD above the mean. Persistently normal SEP predicted normal outcome and persistently abnormal SEP predicted severe disability at follow up. Those with abnormal SEP at 2 months which improved had only moderate or mild disability at follow up. Both of these studies are supported by our data. We also found that those with the most abnormal SEP had suffered the greatest asphyxial insult but, in addition, we found that SEP can be predictive in the neonatal period.

We included data on the cervical response as the presence of a cervical response of normal form and latency shows that any abnomality of cortical response occurs as a result of dysfunction in the central part of the pathway and is not due to peripheral damage as might occur in shoulder dystocia. We did not have access to the technique of electromagnetic stimulation of the motor cortex. ${ }^{17}$ It is motor function that is most often impaired in infants who have sustained asphyxial damage and this technique might have allowed a more specific look at the effects of perinatal asphyxia on the motor pathways during the encephalopathy. However, our hypothesis that abnormality of sensory pathway function might reflect damage in motor areas would seem reasonable.

The effects of sleep state and of drugs must be considered. The first line anticonvulsant used during our study was phenobarbitone and it has been shown to have no effect on SEP. ${ }^{18} 19$ Sleep state is known to alter the waveform and amplitude of the short latency SEP $^{20}{ }^{21}$ but not signficantly to affect the latency, which was the major characteristic we assessed. Sleep state is also altered in encephalopathic infants and any test used has to be employed in the circumstances that present.

We have previously shown that there is a wide range of normal latency for $\mathrm{N} 1$ in the term newborn infant. ${ }^{13}$ We described different waveforms which became increasingly complex with increasing maturity. The abnormalities shown in the asphyxiated infants in this study are mostly profound. Criticism could be levelled at the category of abnormality relating to the inappropriateness of the form or latency for the infant's postmenstrual age. Most of the variation in N1 latency for the whole group of normal infants (SD 6.8 ms) related to a wide range of $\mathrm{Nl}$ in the immature waveforms (immature infants), whereas in the mature forms the SD of $\mathrm{N} 1$ is only $2 \cdot 2 \mathrm{~ms}$. It was therefore thought important to relate results to maturity of the infant as this was the main variable found in normal infants. It is of note that in the more severely asphyxiated infants when the SEP first returned it was in a form which we found associated with the least mature infants and therefore abnormal for that infant's postmenstrual age. This is consistent with findings of the recovery of EEG in sick neonates. ${ }^{22}$ Studies in older children with coma ${ }^{23-25}$ have shown that SEP may be lost early on but rapid recovery of SEP is associated with good outcome and sustained abnormality of SEP correlates with poor outcome. We have shown that this is also the case in perinatal asphyxia.

The only infant (number 20) with appreciable asymmetry of SEP had persisting absence of cortical response on stimulation of the left median nerve until discharge from the unit at 17 days. There was improvement over time from abnormal to normal on right median nerve stimulation. This is demonstrated in fig 3 . Unfortunately he was not subsequently studied. Computed tomography in the neonatal period showed the appearances of neonatal stroke of the right hemisphere and on follow up he had a left hemiplegia. ${ }^{26} 27$

The timing of any neurodevelopmental assessment in a cohort of sick neonates will always have a potential effect on the results. At one year it is relatively easy to pick out those with unequivocally normal outcome and those with cerebral palsy but a grey area will inevitably remain. Later assessment allows more and more scope for profound influences from upbringing and other illness factors. Piper et al, using the Griffiths' assessment, in a cohort of preterm infants examined at 6,12 , and 24 months, showed that at one year $25 \%$ were neurodevelopmentally suspect but only $12 \%$ at two years. ${ }^{28}$ Much of this change was accounted for by movement from the suspect group to frank abnormality. It is likely that some infants in our doubtful group will prove to have clearer abnormalities on later testing.

Prediction of outcome in the perinatally asphyxiated term infant can be difficult but our results suggest that SEP may have a part to play. We were able to confirm that infants with mild encephalopathy all had the same SEP results and a good outcome but that, in addition, a group of infants with moderate encephalopathy and one infant with severe encephalopathy also had the same SEP results and had a normal outcome. In our study the infants with normal potentials by 4 days of age were all neuro- 
developmentally normal on follow up at 1 year of age. None of the infants with abnormal SEP beyond this time had a normal outcome.

The authors are grateful to Dr V Brezinova for neurophysiological advice and to Dr U MacFadyen and Dr B Smith for allowing us to study their patients. Dr Gibson was supported by the Leicestershire health authority locally organised research scheme.

1 Brown JK, Purvis RJ, Forfar JO, Cockburn F. Neurological aspects of perinatal asphyxia. Dev Med Child Neurol 1974; 16:567-80.

2 Sarnat HB, Sarnat MS. Neonatal encephalopathy following fetal distress. Arch Neurol 1976;33:696-705.

3 Ruth VJ, Raivio KO. Perinatal brain damage: predictive value of metabolic acidosis and the Apgar score. BMF 1988; 297:24-7.

4 Archer LNJ, Levene MI, Evans DE. Cerebral artery Doppler ultrasonography for prediction of outcome after perinatal asphyxia. Lancet 1986;ii:1116-7.

5 Holmes G, Rowe J, Hafford J, Schmidt R, Testa M Zimmerman A. Prognostic value of the electroencephalogram in neonatal asphyxia. Electroencephalogr Clin Neuro physiol 1982;53:60-72.

6 Fitzhardinge PM, Flodmark O, Fitz CR, Ashby S. The prognostic value of computed tomography as an adjunct to assessment of the term infant with postasphyxial encephalopathy. F Pediatr 1981;99:777-81.

7 Adsett D, Fitz CR, Hill A. Hypoxic-ischaemic cerebral injury in the term newborn: correlation of CT findings with neurological outcome. Dev Med Child Neurol 1985;27: 155-60.

8 Hrbek A, Karlberg P, Kjellmar I, Olsson T, Riha M. Clinical application of evoked encephalographic responses in newborn infants I: perinatal asphyxia. Dev Med Child Neurol 1977;19:34 44 .

9 Willis J, Duncan C, Bell R. Short-latency somatosensory evoked potentials in perinatal asphyxia. Pediatr Neurol evoked potencia

10 Volpe JJ. Neurology of the newborn. Philadelphia: W B Saunders, 1987

11 Levene MI, Kornberg J, Williams THC. The incidence and severity of post-asphyxial encephalopathy in full-term infants. Early Hum Dev 1985;11:21-6.

12 Koh THHK, Aynsley Green A, Tarbit M, Eyre JA. Neural dysfunction during hypoglycaemia. Arch Dis Child 1988; 63:1353-8.

13 Gibson NA, Brezinova V, Levene MI Somatosensory evoked potentials in the normal term newborn. Electroencephalogr Clin Neurophysiol 1992 (in press.)

14 Griffiths R. The abilities of babies. Amersham: Association for Research in Infant and Child Development, 1954

15 Finer NN, Robertson CM, Richards RT, Pinnell LE, Peters $\mathrm{KL}$. Hypoxic-ischaemic encephalopathy in term neonates perinatal factors and outcome. F Pediatr 1981;98:112-7.

16 Hope PL, Costello AMD, Cady EB, et al. Cerebral energ metabolism studied with phosphorus NMR spectroscopy in normal and birth-asphyxiated infants. Lancet 1984;ii: 366-9.

17 Koh THHK, Eyre JA. Maturation of corticospinal tracts assessed by electromagnetic stimulation of the motor cortex. Arch Dis Child 1988;63:1347-52.

18 Borah NC, Matheshwari MC. Effects of antiepileptic drugs on short latency somatosensory evoked potentials. Acta Neurol Scand 1985;71:331-3.

19 Ganes T, Lundar T. The effect of thiopentone on somatosensory evoked responses and EEG in comatose patients. sensory evoked responses and EEG in coma

20 Hrbek A, Hrbkova M, Lenard H-G. Somato-sensory, auditory and visual evoked responses in newborn infants during sleep and wakefulness. Electroencephalogr Clin Neurophysiol 1969;26:597-603.

21 Willis J. Effects of state and stimulus rate on short latency somatosensory evoked potentials in infants. Ann Neurol 1986;20:411.

22 Ellingson RJ. EEG of fullterm and premature newborns. In: Klass DW, Daly DD, eds. Current practice of clinical electroencephalography. New York: Raven Press, 1981: $149-77$

23 Lutschg J, Pfenninger J, Ludin HP, Vassella F. Brain stem auditory evoked potentials and early somatosensory evoked ly treated comatose children. Am 7 Dis Child 1983;137:421-6.

24 Goff WR, Shaywitz BA, Reisenauer MA, Jasiorkowski JG Venes JL, Rothstein PT. Somatic evoked potential evaluation of cerebral status in Reye syndrome. Electroencephalogr tion of cerebral status in Reye syndro

25 DeMeirleir LJ Taylor MJ. Prognostic utility of SEPs in comatose children. Pediatr Neurol 1987;3:78-82.

26 Mannino FL Trauner DA Stroke in Mannino FL, Trau

27 Ment LR, Duncan CC, Ehrenkrantz RA. Perinatal cerebral infarction. Ann Neurol 1984;16:559-68.

28 Piper MC, Mazer B, Silver KM, Ramsay M. Resolution of neurological symptoms in high risk infants during the first two years of life. Dev Med Child Neurol 1988;30:26-35. 